\title{
Industry Codes of Conduct in a Multi-Layered Dutch Private Law
}

Citation for published version (APA):

Hellegers, D. P. C. M. (2018). Industry Codes of Conduct in a Multi-Layered Dutch Private Law: Bespreking van het proefschrift van mr. M. Menting. Maandblad voor vermogensrecht, 2018(1), 18-21.

https://doi.org/10.5553/MvV/157457672018016001005

\section{DOI:}

10.5553/MvV/157457672018016001005

Document status and date:

Published: 15/02/2018

Document Version:

Early version, also known as pre-print

\section{Document license:}

CC BY-NC-ND

Please check the document version of this publication:

- A submitted manuscript is the version of the article upon submission and before peer-review. There can be important differences between the submitted version and the official published version of record. People interested in the research are advised to contact the author for the final version of the publication, or visit the DOI to the publisher's website.

- The final author version and the galley proof are versions of the publication after peer review.

- The final published version features the final layout of the paper including the volume, issue and page numbers.

Link to publication

\section{General rights}

Copyright and moral rights for the publications made accessible in the public portal are retained by the authors and/or other copyright owners and it is a condition of accessing publications that users recognise and abide by the legal requirements associated with these rights.

- Users may download and print one copy of any publication from the public portal for the purpose of private study or research.

- You may not further distribute the material or use it for any profit-making activity or commercial gain

- You may freely distribute the URL identifying the publication in the public portal.

If the publication is distributed under the terms of Article 25fa of the Dutch Copyright Act, indicated by the "Taverne" license above, please follow below link for the End User Agreement:

https://www.ou.nl/taverne-agreement

Take down policy

If you believe that this document breaches copyright please contact us at:

pure-support@ou.nl

providing details and we will investigate your claim.

Downloaded from https://research.ou.nl/ on date: 26 Apr. 2023 


\title{
Industry Codes of Conduct in a Multi-Layered Dutch Private Law
}

\author{
Bespreking van het proefschrift van mr. M. Menting
}

\author{
Mr.D.P.C.M. Hellegers*
}

\section{Inleiding}

Op 7 december 2016 heeft Marie-Claire Menting aan de Tilburg University haar proefschrift getiteld Industry Codes of Conduct in a Multi-Layered Dutch Private Law verdedigd. ${ }^{1}$ Promotoren waren prof. mr. J.B.M. Vranken en prof. dr. R.A.J. van Gestel. Haar promotieonderzoek is een voortzetting van verkennend empirisch onderzoek, dat zij reeds in het kader van haar masterscriptie heeft verricht, naar de functies van gedragscodes in Europa en Nederland. Ook heeft zij met eerstgenoemde promotor een preadvies geschreven voor de Vereniging voor Burgerlijk Recht onder de titel 'Gedragscodes in een meergelaagd privaatrecht in Europa en Nederland'. Het preadvies is voor een belangrijk deel gebaseerd op en soms letterlijk ontleend aan het proefschrift dat op dat moment in voorbereiding was, zo wordt in het preadvies opgemerkt. ${ }^{3}$

\section{De onderzoeksvragen en het antwoord daarop}

Menting beoogt met haar proefschrift een antwoord te geven op de volgende centrale vraag: 'What is the legal relevance of industry codes of conduct in a multi-layered Dutch private law?'

De keuze van Menting om onderzoek te doen naar de juridische relevantie van gedragscodes die zijn opgesteld op bedrijfstakniveau, onderbouwt zij met de stelling dat gedragscodes die zijn opgesteld op het niveau van multinationale ondernemingen al vaker onderwerp van wetenschappelijk onderzoek zijn geweest, maar dat gedragscodes die zijn opgesteld op bedrijfs-

\footnotetext{
Mr. D.P.C.M. Hellegers is universitair docent privaatrecht bij de Open Universiteit, onderzoeker bij het Amsterdam Centre for Insurance Studies van de UvA en voorzitter van de Geschillencommissies Private Lease, Rijopleidingen, Schadeherstelbedrijven, Tweewielers, Voertuigen en Voertuigverhuur.

De auteur dankt Jac Rinkes voor het beoordelen van de concepttekst van deze recensie en voor de suggesties om die tekst te verbeteren.

1. M. Menting, Industry Codes of Conduct in a Multi-Layered Dutch Private Law (diss. Tilburg), 2016 (369 pagina's).

2. M. Menting \& J.B.M. Vranken, Gedragscodes in een meergelaagd privaatrecht in Europa en Nederland, in: M. Menting, J.B.M. Vranken \& M.W. Scheltema, Gedragscodes in internationaal, Europees en privaatrechtelijk perspectief. Juridische betekenis, effectiviteit en handhaving (Preadviezen 2013 Uitgebracht voor de Vereniging voor Burgerlijk Recht), Zutphen: Uitgeverij Paris 2014, p. 7-59

3. Menting \& Vranken 2014, p. 7.
}

takniveau vanuit wetenschappelijke hoek relatief weinig aandacht hebben gekregen.

Menting heeft haar centrale vraag opgeknipt in de volgende drie deelvragen:

1. 'What are the functions of European and Dutch industry codes of conduct from an empirical perspective?'

2. 'How do the European and the Dutch legislators approach industry codes of conduct in European and Dutch private law and what legal relevance do these actors assign to these codes?'

3. 'How do the Court of Justice of the European Union and the Dutch civil courts approach industry codes of conduct and what legal relevance do these actors assign to these codes?'

Haar proefschrift bestaat uit zeven hoofdstukken. De hoofdstukken 2 en 3 concentreren zich op het beantwoorden van de eerstgenoemde deelvraag. In hoofdstuk 2 komt de opzet van het empirisch onderzoek naar de vraag wat de functies zijn van Europese en Nederlandse gedragscodes die op bedrijfstakniveau zijn opgesteld, aan de orde. Daartoe heeft zij tachtig gedragscodes onderzocht. De uitkomsten van dit onderzoek worden gepresenteerd in hoofdstuk 3, waarbij de functies die zijn geïdentificeerd op basis van het uitgevoerde empirisch onderzoek worden vergeleken met de in de literatuur beschreven functies van gedragscodes. Menting stelt in paragraaf 3.4.2 vast dat uit dit vergelijkend onderzoek niet is gebleken dat uit het empirisch onderzoek nieuwe of andere functies naar voren zijn gekomen dan de functies die op grond van het uitgevoerde literatuuronderzoek zijn geïdentificeerd. In totaal heeft zij vijftien aan elkaar gerelateerde en deels overlappende functies geïdentificeerd. Deze zijn door haar ondergebracht in drie hoofdcategorieën: een regulerende functie, een beleidsfunctie en een communicatieve ofwel signaalfunctie.

In hoofdstuk 4 wordt onderzocht hoe Europese en Nederlandse wetgevers gedragscodes op bedrijfstakniveau gebruiken in het privaatrecht (deelvraag 2). Hiertoe wordt eerst beoordeeld welke ontwikkelingen er binnen het wetgeversbeleid van de Europese en Nederlandse wetgever zijn op het gebied van 
alternatieven voor traditionele op 'command-and-control' gebaseerde systemen van regelgeving. Ten tweede wordt in hoofdstuk 4 nader gekeken naar Europese en Nederlandse wetgeving op het gebied van het privaatrecht waarin wordt verwezen naar gedragscodes op bedrijfstakniveau. Voorts wordt een aantal cases onderzocht waarin de Europese en Nederlandse wetgever via minder zichtbare initiatieven een (initiërende) rol spelen bij gedragscodes op bedrijfstakniveau, bijvoorbeeld door het stimuleren van zelfregulering en coregulering als alternatieven voor wetgeving. Ten derde bevat het hoofdstuk een onderzoek naar criteria voor het gebruik van zelfregulering en coregulering als alternatieven voor wetgeving. Menting concludeert dat gebruikmaking van zelfregulering en coregulering als alternatieven voor wetgeving zich heeft ontwikkeld tot een van de hoekstenen van het wetgevingsbeleid van zowel de Europese als de Nederlandse wetgever. Dit beleid heeft - aldus Menting - ertoe geleid dat de Europese en Nederlandse wetgever het opstellen van gedragscodes op bedrijfstakniveau actief bevorderen, maar ook zelf gedragscodes meeontwikkelen. Zo heeft de Europese wetgever het opstellen van gedragscodes via diverse Europese richtlijnen bevorderd. Een voorbeeld daarvan is art. 37 lid 1 van Richtlijn 2006/123/EG (Dienstenrichtlijn), waarin is bepaald dat de lidstaten in samenwerking met de Commissie flankerende maatregelen dienen te treffen 'om de opstelling, met name door beroepsorden, -organisaties en -verenigingen, op communautair niveau van gedragscodes die gericht zijn op de vergemakkelijking van het verrichten van diensten of de vestiging van een dienstverrichter in een andere lidstaat, met inachtneming van het Gemeenschapsrecht, aan te moedigen'. Bij verschillende gelegenheden heeft de Europese wetgever private partijen actief aangezet tot het ontwikkelen en het gebruik van gedragscodes als alternatief voor of aanvulling op publiekrechtelijke regelgeving. Een voorbeeld daarvan is de totstandkoming van het IAB Europe EU Framework for Online Behavioural Advertising. De Nederlandse wetgever gebruikt gedragscodes op bedrijfstakniveau met name als non-hiërarchisch horizontaal beleidsinstrument in het privaatrecht, zo stelt Menting vast. Uit het onderzoek naar criteria voor het gebruik van zelfregulering en coregulering komt naar voren dat daar op Europees niveau al vaker algemene kaders voor zijn geformuleerd (the Interinstitutional Agreement on Better LawMaking of 2003 (IIA 2003), the Principles for Better Self- and Co-Regulation 2015 en the Interinstitutional Agreement on Better Law-Making (IIA 2016)), terwijl zo'n algemeen kader op Nederlands niveau ontbreekt. $\mathrm{Na}$ vergelijking van het Europese met het Nederlandse beleid concludeert Menting dat het Europese beleid meer uitgaat van een top-downbenadering, die zich uit in een hiërarchische visie op coregulering, een centraal kader met criteria en in Europees privaatrecht opgenomen verwijzingen naar gedragscodes, daar waar de Nederlandse benadering meer bottom-up is. Hierbij wordt gewezen op het meer op consensus gebaseerde concept van coregulering, de ad-hocbenadering als het aankomt op criteria en het nagenoeg ontbreken van verwijzingen naar gedragscodes in het Nederlands privaatrecht.
In de hoofdstukken 5 en 6 beantwoordt Menting deelvraag 3 van haar onderzoek.

In hoofdstuk 5 wordt geanalyseerd hoe het Hof van Justitie van de Europese Unie (HVJ EU) omgaat met gedragscodes die op bedrijfstakniveau zijn opgesteld en welke juridische betekenis het daaraan geeft. Het blijkt dat gedragscodes met name juridisch relevant worden voor het $\mathrm{HvJ} \mathrm{EU}$ op het moment dat deze een beperkende of verstorende werking kunnen hebben op het vrij verkeer en/of mededinging en daardoor onderwerp van rechterlijk onderzoek kunnen worden. $\mathrm{Na}$ een grondige analyse van de jurisprudentie van het $\mathrm{HvJ}$ EU komt Menting allereerst tot de conclusie dat de Europese regels aangaande de vier vrijheden en mededinging de intracommunautaire grenzen bepalen die private partijen bij gebruikmaking van zelfregulering in acht dienen te nemen. Daarnaast blijken private partijen die optreden als regelgever bij naleving van corporate-governanceregels in bepaalde gevallen te worden vrijgesteld van onderzoek naar schending van regels aangaande de vier vrijheden en mededinging. Het $\mathrm{HvJ}$ EU heeft hiermee een juridisch kader geschapen waaraan private regelgeving heeft te voldoen.

In hoofdstuk 6 volgt het onderzoek naar de vraag hoe Nederlandse rechters omgaan met gedragscodes die op bedrijfstakniveau zijn opgesteld en welke juridische betekenis zij daaraan geven. Uit de analyse van uitspraken van de Hoge Raad en de Nederlandse lagere rechtspraak komt - aldus Menting - het beeld naar voren dat lagere rechters (rechtbanken en hoven) in gevallen waarin er geen twijfel bestaat over de toepasselijkheid of bindende kracht van een code, tegenwoordig zonder voorbehoud rekening houden met deze codes. Deze benadering staat volgens haar in schril contrast met de geval-tot-gevalbenadering van de Hoge Raad, waarbij duidelijke criteria lijken te ontbreken op grond waarvan de Hoge Raad tot de beslissing komt om al dan niet juridische relevantie toe te kennen aan gedragscodes. Haar opmerking over het schril contrast tussen de benadering van de Hoge Raad enerzijds en de lagere rechters anderzijds lijkt overigens in contrast te staan met haar in noot 1304 verstopte opmerking dat de Hoge Raad gezien zijn uitspraak in Achmea/Rijnberg lijkt aan te sluiten bij de aanpak van de lagere rechters. ${ }^{4}$ Uit haar onderzoek blijkt echter hoe dan ook dat gedragscodes in de ogen van Nederlandse rechters juridische relevantie kunnen hebben bij het nemen van een beslissing in een privaatrechtelijk geschil, bijvoorbeeld bij de invulling van aansprakelijkheidsnormen.

\section{Enkele kanttekeningen}

Uit het promotiereglement van Tilburg University, alwaar Menting zoals gezegd is gepromoveerd, blijkt dat een promotor, alvorens zijn goedkeuring aan het manuscript te geven, onder meer nagaat of het proefschrift een nieuw inzicht verschaft in de bestaande stand van de gepubliceerde en ter algemene kennisneming openstaande resultaten van de betrokken tak van wetenschap. Daarbij dient hij, blijkens voornoemd

4. HR 18 april 2014, ECLI:NL:HR:2014:942, NJ 2015/20 (Achmea/Rijnberg). 
promotiereglement, met name aandacht te besteden aan het belang van het onderwerp, de helderheid van de probleemstelling, de originaliteit van de behandeling, het wetenschappelijk niveau van de ordening, de analyse en de verwerking van het materiaal, de afleiding van nieuwe inzichten en nieuwe opvattingen uit de analyse, de zuiverheid van de gevolgde methodiek bij de analyse, de vereiste zelfbeperking, een kritische confrontatie van eigen conclusies met bestaande theorieën of opvattingen, een creatieve benadering van het behandelde wetenschapsgebied en evenwicht in de opbouw en helderheid van de stijl.

In het licht van voornoemde criteria verdient Menting een compliment. Haar proefschrift verschaft namelijk zeer zeker een nieuw inzicht in de bestaande stand van de gepubliceerde en ter algemene kennisneming openstaande resultaten aangaande de juridische relevantie van gedragscodes. Het belang van het onderwerp blijkt uit haar proefschrift. De aanpak om de functies die zijn geïdentificeerd op basis van het door haar uitgevoerde empirisch onderzoek te vergelijken met de in de literatuur beschreven functies van gedragscodes is origineel voor het betreffende onderwerp. Dat uit het empirisch onderzoek geen nieuwe of andere functies naar voren zijn gekomen dan de functies die op grond van het uitgevoerde literatuuronderzoek zijn geïdentificeerd, maakt deze vergelijking niet minder waardevol. Het proefschrift acht ik ook evenwichtig opgebouwd.

Enkele meer kritische kanttekeningen zijn ook te plaatsen, die echter geen afbreuk doen aan de waarde van haar werk. Allereerst kan de vraag worden opgeworpen of Menting het begrip 'legal relevance' niet had kunnen operationaliseren naar een maat waarin de juridische relevantie had kunnen worden uitgedrukt. Zie in dit verband het proefschrift van Marc van Opijnen, waarin aandacht wordt besteed aan (de meerwaarde van) het operationaliseren van juridische relevantie. ${ }^{5}$ Een tweede kanttekening betreft het volgende. Het lijkt erop dat Menting haar onderzoek, mede gezien haar opmerkingen en conclusies in onder meer de paragrafen 6.2 en 6.4.3.2 van haar proefschrift, heeft beperkt tot de analyse van literatuur en jurisprudentie waarin regels met een private herkomst in het algemeen en gedragscodes in het bijzonder ter sprake komen. Na deze analyse komt zij in paragraaf 6.5.2 tot de volgende theoretische reflectie aangaande de bindende kracht van gedragscodes:

'However, the civil law cases discussed in this chapter for the most part revolved around the legal relevance of industry codes in the relation between the private actor that applies the code (the regulated actor) and the third-party beneficiaries of these rules, i.e., actors that are the beneficiaries of the rules, yet stand outside the internal private regulator-regulated relationship (such as consumers). Arguably, the fact that many private regulatory schemes

5. M. van Opijnen, Op en in het web. Hoe de toegankelijkheid van rechterlijke uitspraken kan worden verbeterd (diss. Amsterdam UvA), Den Haag: Boom Juridische uitgevers 2014, p. 395-454. are accompanied by enforcement mechanisms that can also be invoked by the third-party beneficiaries reflects that there is also a commitment towards these actors. Yet, from a legal perspective, the binding force lies in the "internal" relation between the regulator and the regulated, except in those cases where the private rules are formally declared applicable to the "external" relationship between the regulated actor and the third-party beneficiaries, in one way or another (e.g., as part of the contract, as a clause in the general terms and conditions or simply by means of a declaration that the code is applicable). However, if such a declaration is lacking, the regulated actors are, strictly speaking, not under a formal obligation to comply with the rules in their external relationship with the third-party beneficiaries. After all, in these cases the regulated actors have only formally undertaken a commitment to follow the rules vis-à-vis the private regulator, not in relation to these beneficiaries. ${ }^{6}$

Meer algemene literatuur en jurisprudentie betrekking hebbende op 'samenhangende rechtsverhoudingen' zijn niet bij het onderzoek betrokken. Zo noem ik in dit verband bijvoorbeeld de proefschriften van M.J. van Laarhoven en C.E. du Perron, het artikel van Lamers en Ernes en de arresten van de Hoge Raad van 24 september 2004 en 20 januari 2012. ${ }^{7} \mathrm{Ik}$ vraag me af of Menting bij een andere afbakening van haar onderzoek en na analyse van meer algemene literatuur en jurisprudentie betrekking hebbende op 'samenhangende rechtsverhoudingen', zoals eerdergenoemde voorbeelden, wellicht wel tot (nadere) criteria had kunnen komen op grond waarvan juridische relevantie aan gedragscodes kan worden toegekend. Ook vraag ik mij af of met name normerende gedragscodes met een externe signaalfunctie (zie hierover p. 47-48 van haar proefschrift) naar hun aard en strekking in de regel niet ook de belangen van derden ('the third-party beneficiaries') op het oog hebben. Zo ja, staat het 'the regulated actor' in dat geval, ook al is er - om in de woorden van Menting te spreken geen sprake van een 'formally declared applicability to the "external" relationship between the regulated actor and the third-party beneficiaries', nog wel vrij de belangen te verwaarlozen die derden bij de behoorlijke nakoming van de gedragscode kunnen hebben? Gezien voornoemde jurisprudentie lijkt dat niet zonder meer het geval te zijn. Wellicht bieden deze opgeworpen vragen ruimte tot vervolgonderzoek.

Tot slot: het lijkt erop dat het proefschrift van Menting niet als handelseditie wordt uitgegeven. Ook is het proefschrift niet openbaar toegankelijk via de Tilburg University Research

6. Menting 2016, p. 254-255.

7. M.J. van Laarhoven, Samenhang in rechtsverhoudingen (diss. Tilburg), Nijmegen: Wolf Legal Publishers 2006; C.E. du Perron, Overeenkomst en derden. Een analyse van de relativiteit van de contractswerking (diss. Amsterdam UvA), Deventer: Kluwer 1999; A.L.H. Ernes \& A.H. Lamers, De begrippen overeenkomst, partij en derde in het civiele recht, AA 2012, afl. 1, p. 26-33; HR 24 september 2004, ECLI:NL:HR: 2004:AO9069, NJ 2008/587 (Vleesmeesters/Alog); HR 20 januari 2012, ECLI:NL:HR:2012:BT7496, NJ 2012/59 (Wierts/Visseren). 
Portal. Dit maakt het proefschrift weinig ontsloten voor geïnteresseerde lezers. Dat is jammer, vooral omdat ik van mening ben dat het proefschrift zeer lezenswaardig is en een schat aan informatie bevat voor onder meer diegenen die regels met een private herkomst in het algemeen en gedragscodes in het bijzonder opstellen of handhaven, of daar een juridische waarde aan willen toekennen. 